\title{
Temporomandibular Disorders: Current Concepts and Controversies in Diagnosis and Management
}

\author{
Dion Tik Shun Li (D) and Yiu Yan Leung * \\ Department of Oral and Maxillofacial Surgery, Faculty of Dentistry, The University of Hong Kong, \\ Hong Kong, China; diontsli@hku.hk \\ * Correspondence: mikeyyleung@hku.hk; Tel.: +852-28890511
}

Citation: Li, D.T.S.; Leung, Y.Y. Temporomandibular Disorders: Current Concepts and Controversies in Diagnosis and Management. Diagnostics 2021, 11, 459. https:// doi.org/10.3390/diagnostics11030459

Academic Editor: Luis

Eduardo Almeida

Received: 17 February 2021

Accepted: 5 March 2021

Published: 6 March 2021

Publisher's Note: MDPI stays neutral with regard to jurisdictional claims in published maps and institutional affiliations.

Copyright: (C) 2021 by the authors. Licensee MDPI, Basel, Switzerland. This article is an open access article distributed under the terms and conditions of the Creative Commons Attribution (CC BY) license (https:// creativecommons.org/licenses/by/ $4.0 /)$.

\begin{abstract}
Temporomandibular disorders (TMD) are a group of orofacial pain conditions which are the most common non-dental pain complaint in the maxillofacial region. Due to the complexity of the etiology, the diagnosis and management of TMD remain a challenge where consensus is still lacking in many aspects. While clinical examination is considered the most important process in the diagnosis of TMD, imaging may serve as a valuable adjunct in selected cases. Depending on the type of TMD, many treatment modalities have been proposed, ranging from conservative options to open surgical procedures. In this review, the authors discuss the present thinking in the etiology and classification of TMD, followed by the diagnostic approach and the current trend and controversies in management.
\end{abstract}

Keywords: temporomandibular disorders; temporomandibular joint; TMD; facial pain; craniomandibular disorders

\section{Introduction}

The diagnosis and management of the most common cause of non-dental pain in the maxillofacial region, namely temporomandibular disorders (TMD), remains a challenge for clinicians to this day, despite extensive clinical research into the topic. This is because TMD is a broad term comprising of different conditions with complex etiologies, with symptoms that vary in intensity. Intriguingly, some signs and symptoms resolve spontaneously even without treatment, whereas others persist for years despite all treatment options having been exhausted. More perplexing is that while some may have a recognizable physical basis, many cases of TMD also involve a significant biopsychosocial component [1-3] with various associated psychological symptoms, such as depression and anxiety [4-6]. Numerous treatment modalities have been proposed over the years, with some becoming obsolete while others are gaining in popularity. Nevertheless, it seems that there is no single solution for every case as many different symptoms are included in TMD. Controversies exist in the literature regarding the diagnosis and the management protocol for TMD, hence the selection of treatment modality may often be largely influenced by the expertise of the treating healthcare provider.

In general, TMD is believed to affect anywhere between 5 and $15 \%$ of adults in the population [7-10], yet TMD related symptoms have been reported to be present in up to $50 \%$ of adults [11]. Interestingly, there is evidence that the prevalence of TMD appears to be on the rise in recent years [12-16]. A recent systematic review and meta-analysis in 2021 concluded that the prevalence of TMD was 31\% for adults and $11 \%$ for children and adolescence [17]. The fact that TMD encompasses a broad assortment of clinical diseases is partially responsible for the wide range of prevalence rate estimates among studies, as the classification of different types of TMD, the distinction between disease and non-disease, as well as whether to include those with inactive disease as having TMD, may all be subject to the partialities of the assessing clinical researchers. In addition, studies that are questionnaire-based might over-estimate the prevalence of TMD, as the symptoms of 
many other conditions, such as headache not caused by TMD, dental pain, neuropathic conditions, and otological diseases, can mimic the presentation of TMD.

TMD represents a significant and complex health problem, with opinions regarding the appropriate course of management often equivocal. In this review, we discuss the current concepts in the etiology and diagnosis of TMD, followed by an up-to-date management approach from a surgeons' perspective.

\section{Etiologies and Classifications}

As an umbrella term for pain and dysfunction of the temporomandibular regions, TMD encompasses a wide variety of clinical conditions. The etiologies of TMD are multifactorial and can be attributed to both physical and psychosocial factors [18-20]. The physical causes can broadly be divided into arthrogenous, and the more common myogenous origins. Many believe that TMD symptoms of arthrogenous origin may be related to internal derangement of the TMJ, which can be defined as a disruption of the internal aspect of the joint, and usually pertains to an articular disc that has been displaced. Although internal derangement does not necessarily lead to pain, it is generally believed that internal derangement precedes degenerative joint diseases, namely osteoarthritis [21]. Osteoarthritis is associated with pain and functional impairment of the TMJ, and is characterized by subchondral bony changes such as cortical erosion and marginal lipping, secondary to pathological changes of the cartilaginous articular disc [22]. Note that the term "osteoarthrosis" has been used as a synonym of osteoarthritis, but also has been used to describe degenerative joint changes of non-inflammatory cause [22]. The severity of internal derangement has been classified by Wilkes into five stages with relations to pain, mouth opening, disc location and anatomy [21]. The classification ranges from painless clicking of the joint (Stage I) to severe pain of the joint with severe degenerative bony changes (Stage V), which has served as an aid to guide treatment options in the management of arthrogenous TMD.

While structural anomalies of the TMJ may predispose the patients to symptoms of TMD [23], it should be noted that not all those with structural abnormalities suffer from the same level of clinical symptoms. Apart from physical causes, the association between biopsychosocial factors and TMD has been described by many $[1-4,19,24]$. Similar to other chronic pain conditions, such as back pain and headache, it appears that there are those in the population who are at risk for developing symptomatic TMD, who also share a certain psychological profile and dysfunction $[25,26]$. Higher levels of depression and somatization are associated with TMD of arthrogenous and myogenous origins [27]. Moreover, in those with pre-existing TMD, symptoms may be exacerbated during times of stressful events. For example, recent studies have suggested that the during periods of lockdown and social isolation due to the ongoing COVID-19 pandemic, an impact was found on the prevalence of depressive symptoms, stress, as well as pain related to TMD [28,29]. The finding that psychological variables are closely tied to the development of TMD has been confirmed by the Orofacial Pain: Prospective Evaluation and Risk Assessment (OPPERA) study, which found that TMD onset was strongly associated with somatic symptoms, while previous life events, perceived stress and negative affect were also associated with the incidence of TMD [30].

What makes the diagnosis and classification of TMD complicated at times is that many patients present with multiple diagnoses of TMD simultaneously, and it is impossible to isolate the condition to a single particular cause. When discussing about TMD, most clinical researchers refer to those pain conditions that are most commonly seen. However, one must not forget that disorders related to the TMJ include those that are less routinely encountered. Importantly, the presentation of these uncommon conditions of the TMJ may initially mimic those of the more common TMD, yet the management approach may be completely different. For example, a patient who presents with ankylosis of the TMJ may initially present with signs and symptoms similar to closed-lock due to disc displacement, but the standard treatment for ankylosis is surgical release of ankylosis, while conservative 
or minimally invasive options, such as arthrocentesis, are usually indicated for closed-lock of the TMJ due to disc displacement.

The crude classification of the most common diagnoses of TMD into arthrogenous, myogenous, or of mixed origin is helpful in steering the clinician into the appropriate path in the initial phases of management. However, more specific diagnoses are usually required, especially if the management progresses beyond conservative options. In the past, classification was often confusing, with many different terminologies referring to similar entities. Today, the Diagnostic Criteria for Temporomandibular Disorders (DC/TMD) is the most widely accepted and standardized tool for assessment and classification of TMD, with sensitivity and specificity established for the most common diagnoses of TMD [31]. Recognizing that TMD contains a structural as well as a biopsychosocial component, the DC/TMD consists of two Axes in its assessment. Axis-I contains a protocol for a prescribed physical examination to arrive at specific physical diagnoses of TMD with regard to the joint and musculature, while Axis-II contains several instruments to assess the psychological state of the patient.

There are 12 most common diagnoses of TMD described in Axis-I of the DC/TMD, which are divided into painful conditions (myalgia, local myalgia, myofascial pain, myofascial pain with referral, arthralgia, headache attributed to TMD) and non-painful conditions (disc displacement with reduction, disc displacement with reduction with intermittent locking, disc displacement without reduction with limited opening, disc displacement without reduction without limited opening, degenerative joint disease, subluxation) [31] (Table 1). Note that in many cases, multiple diagnoses are present at any timepoint in a single patient, and that diagnoses may change as the disease progresses or resolves. For example, a patient with complaints of joint clicking with pain in the TMJ and masseter muscle, and headache during mouth opening may be diagnosed with having local myalgia, arthralgia, disc displacement with reduction, and headache attributed to TMD. The classification of TMD also includes those that are less common, but clinically important diseases [32]. Some of these less common diagnoses include fractures of the TMJ, manifestations of systemic diseases, as well as rare conditions such as neoplasms and developmental disorders (Table 2) [32]. However, when these diagnoses do not fit the clinical symptoms, other conditions should also be considered.

Table 1. Common diagnoses of temporomandibular disorders (TMD) and their clinical findings.

\begin{tabular}{ll}
\hline Painful Conditions & Clinical Findings \\
\hline Myalgia & $\begin{array}{l}\text { Familiar pain in the masseter or temporalis } \\
\text { upon palpation or mouth opening }\end{array}$ \\
\hline Local Myalgia & $\begin{array}{l}\text { Familiar pain in the masseter or temporalis } \\
\text { localized to the site of palpation }\end{array}$ \\
\hline Myofascial pain & $\begin{array}{l}\text { Pain in the masseter or temporalis spreading } \\
\text { beyond the site of palpation but within the } \\
\text { confines of the muscle }\end{array}$ \\
\hline Myofascial pain with referral & $\begin{array}{l}\text { Pain in the masseter or temporalis beyond the } \\
\text { confines of the muscle being palpated }\end{array}$ \\
\hline Arthralgia & $\begin{array}{l}\text { Familiar pain in the TMJ upon palpation or } \\
\text { during function }\end{array}$ \\
\hline Headache attributed to TMD & $\begin{array}{l}\text { Headache in the temple upon palpation of the } \\
\text { temporalis muscle or during function }\end{array}$ \\
\hline
\end{tabular}


Table 1. Cont.

\begin{tabular}{ll}
\hline Non-Painful Conditions & Clinical Findings \\
\hline Disc displacement with reduction & Clicking in the TMJ upon function \\
\hline $\begin{array}{l}\text { Disc displacement with reduction with } \\
\text { intermittent locking }\end{array}$ & $\begin{array}{l}\text { Clicking in the TMJ with reported episodes of } \\
\text { limited mouth opening }\end{array}$ \\
\hline $\begin{array}{l}\text { Disc displacement without reduction with } \\
\text { limited opening }\end{array}$ & $\begin{array}{l}\text { Limited mouth opening affecting function, } \\
\text { with maximum assisted opening }<40 \mathrm{~mm}\end{array}$ \\
\hline $\begin{array}{l}\text { Disc displacement without reduction without } \\
\text { limited opening }\end{array}$ & $\begin{array}{l}\text { Limited mouth opening affecting function, } \\
\text { with maximum assisted opening of } \geq 40 \mathrm{~mm}\end{array}$ \\
\hline Degenerative joint disease & \begin{tabular}{l} 
Crepitus of the TMJ upon function \\
\hline Subluxation
\end{tabular} \\
\hline $\begin{array}{l}\text { History of jaw locking in an open mouth } \\
\text { position, cannot close without a self-maneuver }\end{array}$
\end{tabular}

Modified from Schiffman et al., 2014 [31].

Table 2. Some less common diagnoses of temporomandibular disorders (TMD).

\section{TMJ}

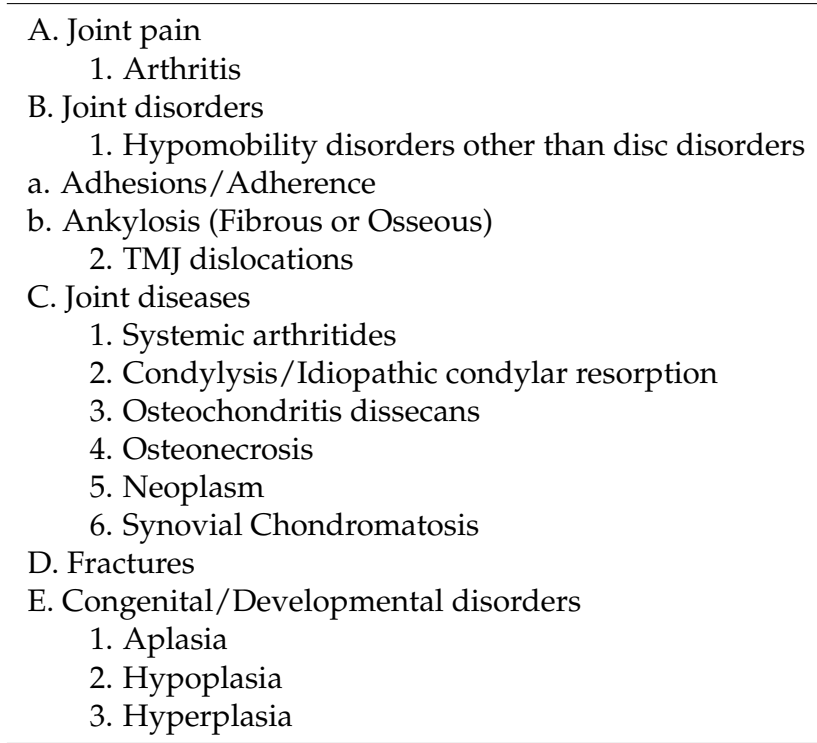

\section{Masticatory Muscles}

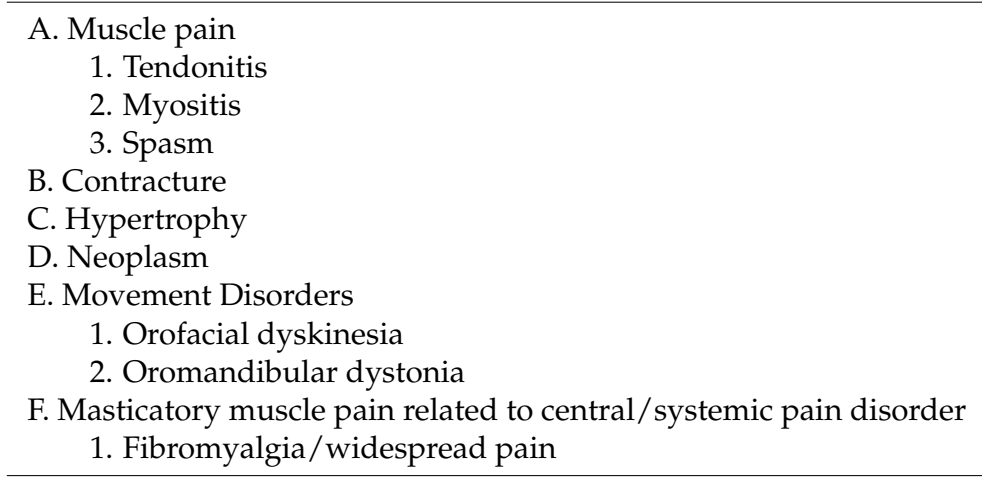

\section{Associated Structures}

A. Coronoid hyperplasia Modified from Peck et al., 2014 [32].

\section{Diagnostic Approach}

The signs and symptoms of TMD may mimic other orofacial pain conditions. Although precise physical diagnosis into the type of TMD is helpful in developing an appropriate 
treatment plan, it might not be straight forward in every case. Taking a patients' history is an important part of diagnosing the TMJ condition. The acquisition of history follows the usual format. Apart from the chief complaint, inquiries should be made regarding any history of trauma or previous episodes, aggravating factors, such as eating, talking, yawning or spontaneous background pain, and any previous investigations or treatment. The severity of pain should also be graded using a visual analogue scale (VAS), so treatment progress can be quantitatively monitored. A past and current medical history, including a full medications list, may reveal any comorbidities that may be related to TMD. The clinician should note any habits such as smoking, drinking and recreational drug use, and any history of clenching or bruxism as complained by the patients' bed partner. Additionally, the clinician should ask questions regarding stress and level of life satisfaction, and whether there are any recent life events, such as change of job or loss of a loved one. Although most clinicians treating TMD may be experienced with acquiring a clinical history, some may not be comfortable with taking a psychological history. If desired, the clinician may employ the numerous psychosocial instruments available to aid in their diagnosis, such as those in Axis-II of DC/TMD [31]. When necessary, the patient may be referred for a psychological assessment.

Most clinicians who treat orofacial pain believe clinical examination is the most crucial process of diagnosing TMD. The location of pain, and whether the pain is localized, remains within or spreads beyond the confines of the muscle, should be confirmed with palpation, which is done at rest and during mandibular function. Clicking or crepitus upon mandibular function might be quite obvious in some cases, and the detection might be aided by the use of a stethoscope. Intriguingly, the presence or location of clicking detected by the clinician might be different from that reported by the patient, and this should be documented. The range of mouth opening measured should include pain-free maximum mouth opening, maximum unassisted mouth opening, and maximum assisted mouth opening. Any deviation of the mandible may indicate differential obstruction of the movement of the mandibular condyle in rotation and/or translation. An intra-oral examination is performed to rule out any mucosal pathologies of the oral cavity and oropharyngeal region, as well as to assess the state of the dentition.

\subsection{Imaging and Other Investigations}

Imaging is considered to be a useful adjunct in the diagnosis of TMD. Although the diagnostic information provided by plain radiographs like orthopantomogram is limited, they are convenient, simple and serve to rule out some of the differential diagnoses of the bony TMJ, such as fractures, ankylosis, growth disturbances, as well as neoplasms. For the most common types of TMD which clinical presentation is typical, many units might not routinely employ additional imaging. This is due to availability and cost, and that additional imaging might not alter the initial management plan. However, when further information is desired, magnetic resonance imaging (MRI) is the gold standard for TMJ imaging, and is useful in assessing the status of the osseous, as well as the non-osseous structures of the TMJ, such as the masticatory muscles, ligaments and the cartilaginous disc [33] (Figure 1). Classification systems, such as Wilkes [21], combine clinical and MRI findings to stage the extent of internal derangement in order to guide treatment protocol. MRI is therefore considered mandatory prior to any surgical intervention.

While MRI is the most commonly used diagnostic imaging for the common diagnoses of TMD, other imaging modalities are also employed for specific indications. Cone-beam computed tomography (CBCT) has been used to further assess the osseous structure of the TMJ [34-36]. This may be desirable in cases of TMJ ankylosis, benign bony neoplasms or overgrowth, or for the planning of osseous surgery, such as for eminectomy for recurrence TMJ dislocation. However, for most other diagnoses of TMJ, the value of CBCT is not well-established since the information provided in terms of soft tissues is limited [36]. Moreover, the use of ultrasound as a diagnostic tool for TMD has been suggested [15,37,38]. Ultrasound has the advantages of being non-invasive, cheap, and widely available in many 
health institutions, yet the effectiveness as a diagnostic method remains to be confirmed [15]. For some inflammatory conditions of the TMJ, such as osteoarthritis and joint inflammation, bone scintigraphy may be of value as a diagnostic tool [39-43]. Moreover, bone scintigraphy has been proposed as a method for the evaluation of active TMJ condylar growth, but it has been shown that both the sensitivity and specificity are low for this indication [44].

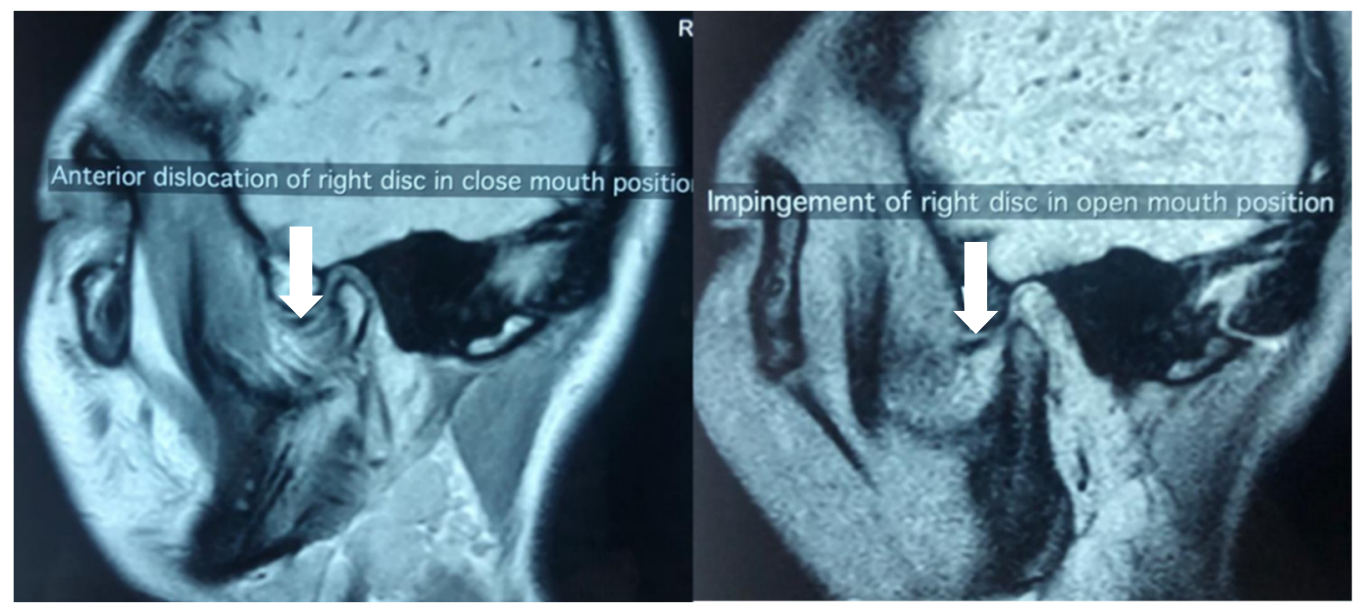

Figure 1. Magnetic resonance imaging (MRI) showing anteriorly displaced disc in both the close and open mouth position in a patient presented with lock jaw.

Apart from the different imaging modalities available, other investigations are not commonly done for most diagnoses of TMD, except in specific indications. For example, blood investigations may be done for TMD related to systemic conditions, such as rheumatoid arthritis or gout. In the case of uncertain diagnoses of rare diseases or neoplasms, tissue biopsies might be taken, which may be done by fine-needle aspiration, arthroscopic or open joint approach.

\subsection{Diagnosis of TMD}

Recognizing the causes of pain and dysfunction related to TMD is important in order to guide treatment decisions. For instance, different treatment options are often employed for the treatment of myogenous versus arthrogenous TMD. Moreover, in those patients who present with TMD symptoms without an obvious physical cause, who also suffer from psychological comorbidities, may be best treated by counselling and psychological intervention.

The most important part of the diagnosis of TMD is to differentiate the common diseases from those clinically significant, but unusual conditions, as well as conditions that are more serious which urgent attention is needed. For example, some neoplasms, such as chondrosarcoma of the TMJ may initially share signs and symptoms as some of the common diagnoses of TMD, such as pain at the preauricular region and limited opening. Another example that requires urgent attention is temporal arteritis, which is an inflammatory condition of the temporal vessels with some TMD-like symptoms, such as headache, pain in the temporal region, and limited mouth opening. However, temporal arteritis is a medical emergency which may cause permanent blindness if not treated promptly. Some of the differential diagnoses of orofacial pain that may mimic TMD are listed in Table 3 [45]. 
Table 3. Differential diagnosis of temporomandibular disorders (TMD).

\begin{tabular}{ll}
\hline & Neuropathic Pain \\
\hline Trigeminal neuralgia & \\
Glossopharyngeal neuralgia & \\
Postherpetic neuralgia & \\
Traumatic neuralgia & \\
Burning mouth syndrome & Atypical odontalgia \\
Atypical facial pain
\end{tabular}

Odontogenic Pain

\author{
Dental caries \\ Periodontal disease \\ Dental abscess \\ Dental sensitivity \\ Cracked tooth syndrome \\ Periocoronitis
}

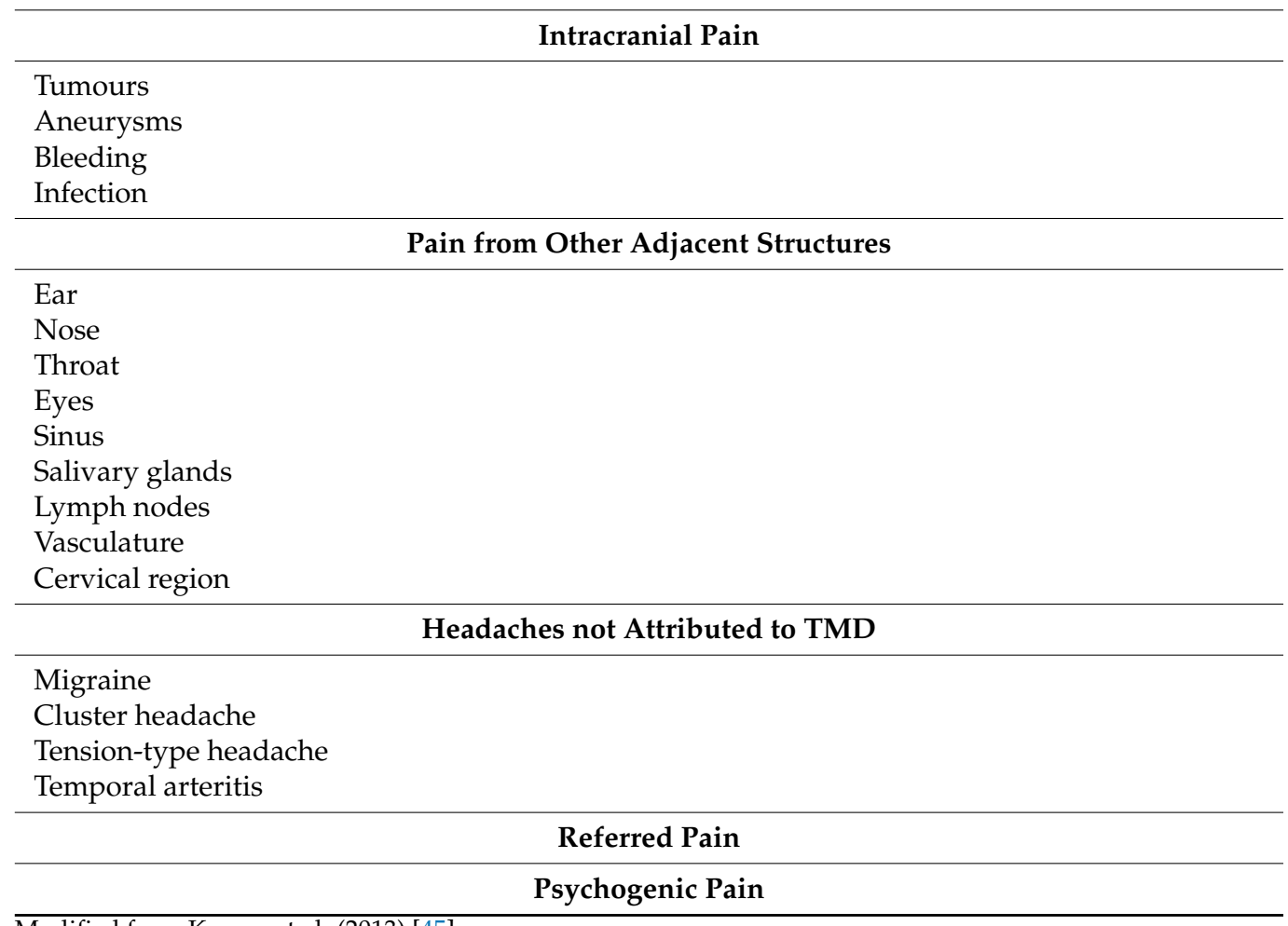

\section{Treatment Modalities-A Change in Paradigm?}

The goals of treatment for TMD include reduction of pain and improvement of jaw function. Additionally, treatment with the goal of behavioural change may be important in the reduction of tension and parafunction. Currently, physically restoring the disc position in the case of internal derangement is not the primary treatment objective as it may not be relevant to clinical improvement $[46,47]$, unless of course if there is inflammation related to disc displacement then it should be addressed. Symptoms of TMD should be addressed promptly, as chronic pain becomes more difficult to manage due to psychological deterioration and somatization $[2,19]$. Since conservative options are less likely to cause any harm, they are usually indicated in the early stages of treatment. This is especially true when definitive diagnosis is difficult to ascertain and treatment is performed empirically. However, there is no agreement on how long conservative treatment should be attempted before progressing to other options when clear benefits are not observed. Although the treatment of TMD has shifted away from open procedures which were once popular, 
the demonstrated success of minimally invasive options may indicate that they may be considered as an early option for those cases refractory to conservatory approaches.

\subsection{Conservative Options}

The initial management of TMD may include various medications, such as analgesics, non-steroidal anti-inflammatory drugs (NSAIDs), anxiolytics, and anti-depressants. Occlusal appliances of various designs are routinely prescribed, which represent a noninvasive option with minimal risks (Figure 2). The use of occlusal splint therapy has been shown to reduce pain intensity and increase maximal mouth opening [48]. However, whether the effect of an occlusal splint is due to the placebo effect has been questioned, and that the evidence of its efficacy remains to be low [49,50]. A systematic review in 2018 by Alkhutari et al. has suggested that the use of occlusal splint may improve patient-centred treatment outcomes, which may be more than merely a placebo effect [51]. Multiple designs are available, such as hard, soft, and anterior repositioning splint. At present, there is no consensus on which design is superior, as results from different studies are equivocal in terms of the efficacy of different designs of occlusal splints [50,52].

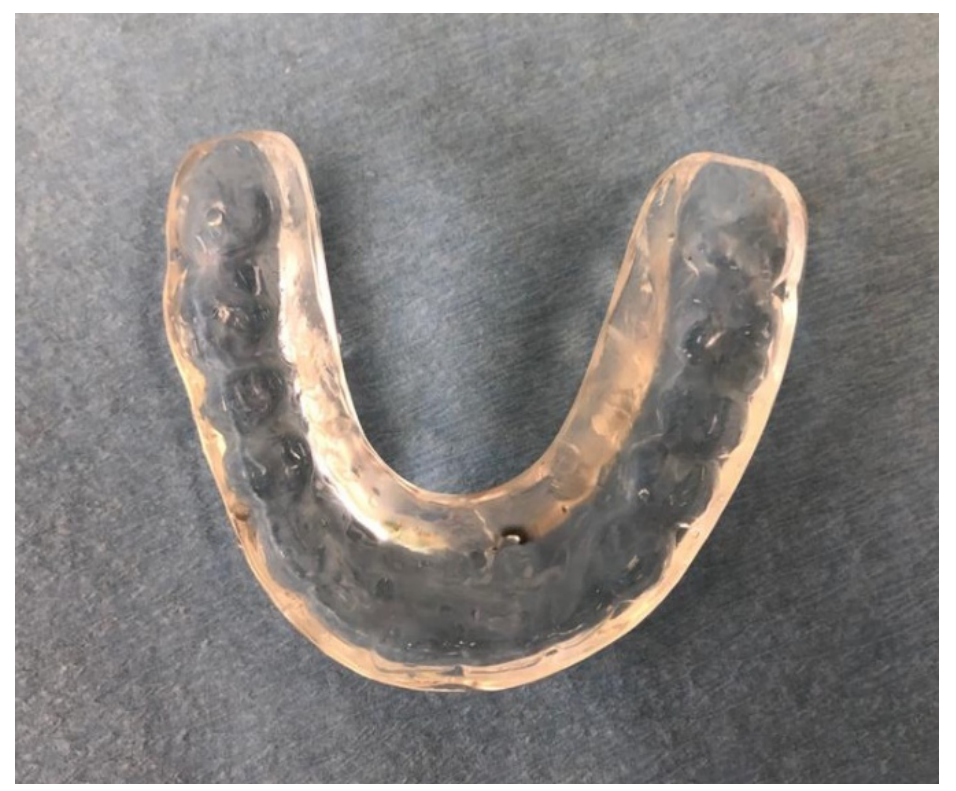

Figure 2. Occlusal splint for the management of temporomandibular disorders (TMD) and bruxism.

Physiotherapy has been suggested to be an important part in the management of TMD [53,54], which may be particularly useful for myalgia or myofascial pain. Understanding the loading of the stomatognathic system, and the existence of any tension and parafunctions, is important in delivering physiotherapy such as muscle training and changing of behaviour. Evidence shows that physiotherapy is effective in treatment of TMD, in particular the headache symptoms associated with the condition; future research into this area will further ascertain these findings [54]. For myogenous TMD, Botox injection and dry-needling techniques have been suggested [55,56]. Note that Botox is not considered a standard treatment option for TMD, while dry-needling, or acupuncture, may be an effective method to reduce tension in some patients. Additionally, initial results regarding extracorporeal shock wave therapy for myogenous TMD appear to show positive results [57,58].

There has been increasing evidence demonstrating that psychosocial assessment serves as a powerful tool in terms of predicting treatment outcome $[59,60]$. For those patients with a significant psychosocial component, counselling seems to be a promising treatment adjunct [50,61-63], which might be most beneficial when included in a multimodal approach [50]. Other conservative treatment options for TMD include stress reduction 
techniques and diet modification. In the past, a causative relationship between occlusion and TMD had been suggested, but it is now considered an outdated theory not supported by robust evidence, and occlusal adjustment is an irreversible treatment which is no longer supported by the recent literature [64-67].

\subsection{Minimally Invasive Options-Arthroscopy, Arthrocentesis and Intra-Articular Injections}

In the 1980s, the availability of MRI has led clinicians to acknowledge the structural anomalies related to TMD. This has resulted in a boom of open joint surgeries, which were unfortunately ineffective in the most part. For those cases of TMD that are arthrogenous and not responsive to conservative treatment, more focus has since been shifted to minimally invasive procedures which have shown promising clinical results.

Arthroscopy of the TMJ was initially pioneered by the Japanese in the 1970s [68,69], and later popularized by the Americans [70-72]. TMJ arthroscopy may involve lysis and lavage of the superior joint space, as well as operative procedures, such as repositioning of a displaced disc, arthroplasty, and removal of inflamed tissues and adhesions. The efficacy of arthroscopy has since been well-recognized [73-79], and has been found that the therapeutic effect was mainly due to lysis and lavage but not disc position [80]. It was due to this finding that a modification was made, where lysis and lavage was performed without arthroscopic view. This was termed arthrocentesis which was first described by Nitzan et al., in 1991 [81], with efficacy that has since been well-documented [46,82-94] (Figure 3).

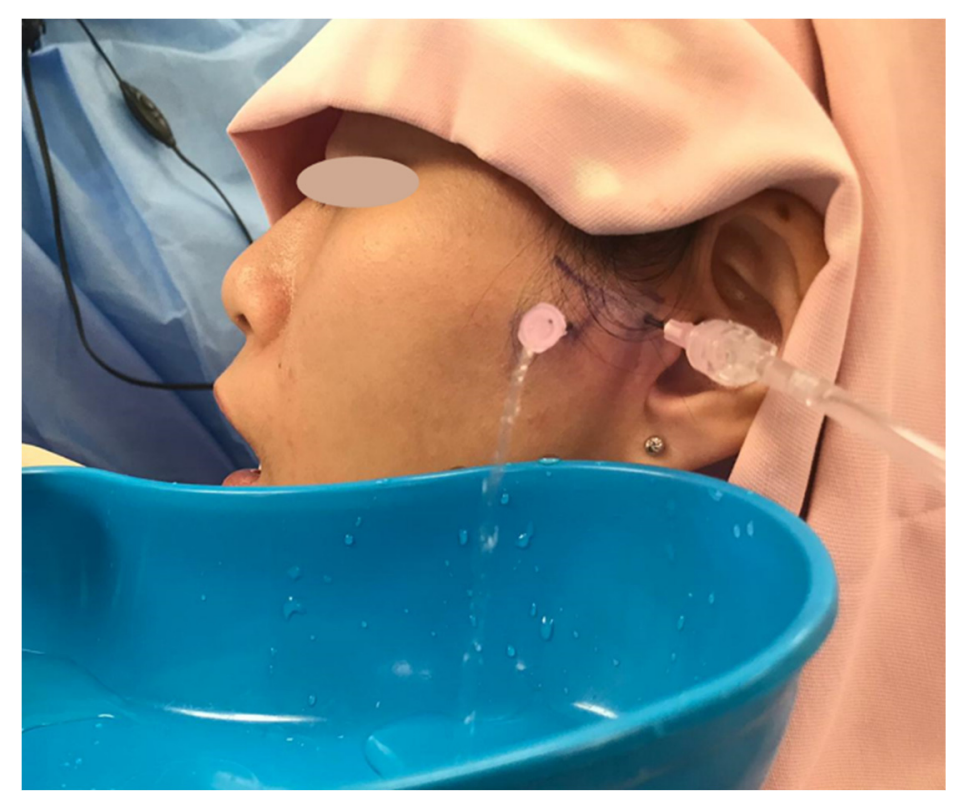

Figure 3. Arthrocentesis performed under local anaesthesia.

In addition to the shift from open joint surgery to minimally invasive treatment for those cases not responsive to conservative treatment, recent literature seems to support that minimally invasive options may be attempted early for arthrogenous TMD [95,96], and this may represent a paradigm shift in the management protocol. A recent integrated review and meta-analysis performed by the authors of this article showed that arthrocentesis was beneficial, whether it was performed as an initial treatment, as an early or late treatment with regard to conservative treatment [97]. However, the best timing to perform arthrocentesis is still unclear due to the paucity of research on the topic, which warrants more future well-designed clinical trials [97].

Although both arthroscopy and arthrocentesis have been shown to be beneficial in the treatment of TMD, it is unclear which method produces better clinical results. In a systematic review and meta-analysis by Al-Moraissi, it was revealed that arthroscopy was 
superior to arthrocentesis in pain reduction and jaw function improvement, with similar complication rates for both methods [78]. However, other studies have shown comparable results with the two procedures $[98,99]$. Nevertheless, arthrocentesis has been suggested to be attempted first due to simplicity and cost-effectiveness, with a similar or potentially lower complication rate [99].

Several modifications have been suggested for the conventional arthrocentesis, which involves two puncture needles into the superior joint space guided by landmarks in relations to adjacent structures, followed by lavage with an irrigation solution. For example, single-puncture techniques employ specially designed devices, and may have both the inflow and outflow fluid going through a single cannula but with different ports. Although single-puncture techniques may appear more simple than double-puncture arthrocentesis, most studies to date have shown a similar clinical outcome between the two techniques [83,100-102]. In addition, ultrasound-guided arthrocentesis has been proposed to increase the accuracy of puncture into the superior joint space [103-106]. However, a recent systematic review by Leung et al. has shown that no additional benefit is seen with ultrasound-guided arthrocentesis compared to conventional arthrocentesis [107]. Furthermore, different pharmacological agents for intra-articular injection have been proposed, with the common ones including hyaluronic acid, corticosteroid, analgesics, and plateletrich plasma $[93,96,108,109]$. Although promising results are seen in some studies, there is currently no consensus regarding which intra-articular injection agent is superior over the others.

Despite the reported efficacy, arthroscopy is seldom required in TMD patients, even in cases of true arthrogenous disorders. Additionally, arthrocentesis is still considered to be a controversial procedure [87], despite the documented efficacy and low complication rates. The reasons for this controversy are as follows. Firstly, some cases of TMD improve with mere conservative options, or even without treatment. Additionally, many cases of TMD are due to multiple etiologies, which may require a multimodal approach before any clear clinical improvement can be appreciated. In addition, intra-articular injection of corticosteroids is a simple and very effective treatment, which may be attempted prior to arthrocentesis. In short, minimally invasive procedures may be the answer in those patients with true arthrogenous TMD not responsive to conservative treatment options, whose condition also lack a significant biopsychosocial component.

\subsection{Open Joint Surgery}

Open surgical treatment for TMD is now uncommon, and is reserved for specific indications as well as end-stage diseases. Though, surgery may be the only viable option in some conditions, such as ankylosis and neoplasms, which require release of ankylosis and removal of tumour, respectively. Pending on the availability of equipment and skills, there is now an option of arthroscopic surgery for procedures that were only performed with an open-joint approach in the past. These procedures include disc repositioning procedures, removal of osteophyte, removal of pathologic tissue, and biopsy of the TMJ. In recent years, much work has been done regarding replacement of the TMJ with alloplastic prosthesis [110-116] with an observed improvement in prognosis and longevity. Due to this success, it is likely that we will see a continuous increase in popularity of alloplastic replacement of the TMJ for conditions such as end stage arthritic conditions, ankylosis, post-tumour resection, and developmental anomalies of the TMJ.

\section{Conclusions}

TMD represents a divergent group of orofacial pain symptoms which shares similarities with other chronic pain conditions. The etiology of TMD is often multi-factorial, and precise causes for the symptoms may be difficult to pinpoint. In the past, focus has been placed on the physical origins of TMD, but an at least equally significant psychosocial factor is now well-recognized. Consequently, a multimodal approach, which might include counselling and psychological therapy, is being increasingly advocated. Most instances of 
TMD are managed conservatively and empirically during the early phases of treatment, yet lingering in the conservative phase for an extended period when clinical improvement is unclear is not recommended. Though open joint surgery is rare nowadays and is reserved for specific situations, we may be in the midst of a changing paradigm which favours early minimally invasive procedures.

Author Contributions: Both authors are responsible for all parts of the work. All authors have read and agreed to the published version of the manuscript.

Funding: This research received no external funding.

Conflicts of Interest: The authors declare no conflict of interest.

\section{References}

1. Von Korff, M.; Ormel, J.; Keefe, F.J.; Dworkin, S.F. Grading the severity of chronic pain. Pain 1992, 50, 133-149. [CrossRef]

2. Ismail, F.; Eisenburger, M.; Lange, K.; Schneller, T.; Schwabe, L.; Strempel, J.; Stiesch, M. Identification of psychological comorbidity in TMD-patients. Cranio 2016, 34, 182-187. [CrossRef] [PubMed]

3. List, T.; Jensen, R.H. Temporomandibular disorders: Old ideas and new concepts. Cephalalgia 2017, 37, 692-704. [CrossRef] [PubMed]

4. Bitiniene, D.; Zamaliauskiene, R.; Kubilius, R.; Leketas, M.; Gailius, T.; Smirnovaite, K. Quality of life in patients with temporomandibular disorders. A systematic review. Stomatologija 2018, 20, 3-9. [PubMed]

5. Resende, C.; Rocha, L.; Paiva, R.P.; Cavalcanti, C.D.S.; Almeida, E.O.; Roncalli, A.G.; Barbosa, G.A.S. Relationship between anxiety, quality of life, and sociodemographic characteristics and temporomandibular disorder. Oral Surg. Oral Med. Oral Pathol. Oral Radiol. 2020, 129, 125-132. [CrossRef] [PubMed]

6. Dahlstrom, L.; Carlsson, G.E. Temporomandibular disorders and oral health-related quality of life. A systematic review. Acta Odontol. Scand. 2010, 68, 80-85. [CrossRef]

7. Goncalves, D.A.; Camparis, C.M.; Speciali, J.G.; Franco, A.L.; Castanharo, S.M.; Bigal, M.E. Temporomandibular disorders are differentially associated with headache diagnoses: A controlled study. Clin. J. Pain 2011, 27, 611-615. [CrossRef]

8. Lim, P.F.; Smith, S.; Bhalang, K.; Slade, G.D.; Maixner, W. Development of temporomandibular disorders is associated with greater bodily pain experience. Clin. J. Pain 2010, 26, 116-120. [CrossRef] [PubMed]

9. Facial Pain. Available online: http:/ / www.nidcr.nih.gov/DataStatistics/FindDataByTopic/FacialPain/ (accessed on 9 June 2019).

10. Lipton, J.A.; Ship, J.A.; Larach-Robinson, D. Estimated prevalence and distribution of reported orofacial pain in the United States. J. Am. Dental Assoc. 1993, 124, 115-121. [CrossRef] [PubMed]

11. Locker, D.; Slade, G. Prevalence of symptoms associated with temporomandibular disorders in a Canadian population. Community Dent. Oral Epidemiol. 1988, 16, 310-313. [CrossRef]

12. Magnusson, T.; Egermark, I.; Carlsson, G.E. A longitudinal epidemiologic study of signs and symptoms of temporomandibular disorders from 15 to 35 years of age. J. Orofac. Pain 2000, 14, 310-319.

13. Ebrahimi, M.; Dashti, H.; Mehrabkhani, M.; Arghavani, M.; Daneshvar-Mozafari, A. Temporomandibular Disorders and Related Factors in a Group of Iranian Adolescents: A Cross-sectional Survey. J. Dent. Res. Dent. Clin. Dent. Prospect. 2011, 5, 123-127. [CrossRef]

14. Manfredini, D.; Piccotti, F.; Ferronato, G.; Guarda-Nardini, L. Age peaks of different RDC/TMD diagnoses in a patient population. J. Dent. 2010, 38, 392-399. [CrossRef] [PubMed]

15. Klatkiewicz, T.; Gawriolek, K.; Pobudek Radzikowska, M.; Czajka-Jakubowska, A. Ultrasonography in the Diagnosis of Temporomandibular Disorders: A Meta-Analysis. Med. Sci. Monit. 2018, 24, 812-817. [CrossRef] [PubMed]

16. Sena, M.F.; Mesquita, K.S.; Santos, F.R.; Silva, F.W.; Serrano, K.V. Prevalence of temporomandibular dysfunction in children and adolescents. Rev. Paul. Pediatr. 2013, 31, 538-545. [CrossRef] [PubMed]

17. Valesan, L.F.; Da-Cas, C.D.; Reus, J.C.; Denardin, A.C.S.; Garanhani, R.R.; Bonotto, D.; Januzzi, E.; de Souza, B.D.M. Prevalence of temporomandibular joint disorders: A systematic review and meta-analysis. Clin. Oral Investig. 2021. [CrossRef] [PubMed]

18. Rollman, G.B.; Gillespie, J.M. The role of psychosocial factors in temporomandibular disorders. Curr. Rev. Pain 2000, 4, 71-81. [CrossRef] [PubMed]

19. Auerbach, S.M.; Laskin, D.M.; Frantsve, L.M.; Orr, T. Depression, pain, exposure to stressful life events, and long-term outcomes in temporomandibular disorder patients. J. Oral Maxillofac. Surg. 2001, 59, 628-633. [CrossRef]

20. Toh, A.Q.J.; Chan, J.L.H.; Leung, Y.Y. Mandibular asymmetry as a possible etiopathologic factor in temporomandibular disorder: A prospective cohort of 134 patients. Clin. Oral Investig. 2021. [CrossRef] [PubMed]

21. Wilkes, C.H. Internal Derangements of the Temporomandibular Joint: Pathological Variations. Arch. Otolaryngol. Head Neck Surg. 1989, 115, 469-477. [CrossRef]

22. Mercuri, L.G. Osteoarthritis, osteoarthrosis, and idiopathic condylar resorption. Oral Maxillofac. Surg. Clin. N. Am. 2008, 20, 169-183. [CrossRef]

23. Bertram, S.; Rudisch, A.; Innerhofer, K.; Pümpel, E.; Grubwieser, G.; Emshoff, R. Diagnosing TMJ internal derangement and osteoarthritis with magnetic resonance imaging. J. Am. Dent. Assoc. 2001, 132, 753-761. [CrossRef] 
24. Turk, D.C.; Gatchel, R.J. Psychological Approaches to Pain Management: A Practitioner's Hand Book; The Gilford Press: New York, NY, USA, 2002.

25. Dworkin, S.F.; Massoth, D.L. Temporomandibular disorders and chronic pain: Disease or illness? J. Prosthet. Dent. 1994, 72, 29-38. [CrossRef]

26. Suvinen, T.I.; Reade, P.C. Temporomandibular disorders: A critical review of the nature of pain and its assessment. J. Orofac. Pain 1995, 9, 317-339. [PubMed]

27. Yap, A.U.; Tan, K.B.; Chua, E.K.; Tan, H.H. Depression and somatization in patients with temporomandibular disorders. J. Prosthet. Dent. 2002, 88, 479-484. [CrossRef] [PubMed]

28. Saccomanno, S.; Bernabei, M.; Scoppa, F.; Pirino, A.; Mastrapasqua, R.; Visco, M.A. Coronavirus Lockdown as a Major Life Stressor: Does It Affect TMD Symptoms? Int. J. Environ. Res. Public Health 2020, 17, 8907. [CrossRef]

29. Medeiros, R.A.; Vieira, D.L.; Silva, E.; Rezende, L.; Santos, R.W.D.; Tabata, L.F. Prevalence of symptoms of temporomandibular disorders, oral behaviors, anxiety, and depression in Dentistry students during the period of social isolation due to COVID-19. J. Appl. Oral Sci. 2020, 28, e20200445. [CrossRef]

30. Fillingim, R.B.; Ohrbach, R.; Greenspan, J.D.; Knott, C.; Diatchenko, L.; Dubner, R.; Bair, E.; Baraian, C.; Mack, N.; Slade, G.D.; et al. Psychological factors associated with development of TMD: The OPPERA prospective cohort study. J. Pain Off. J. Am. Pain Soc. 2013, 14, T75-T90. [CrossRef] [PubMed]

31. Schiffman, E.; Ohrbach, R.; Truelove, E.; Look, J.; Anderson, G.; Goulet, J.P.; List, T.; Svensson, P.; Gonzalez, Y.; Lobbezoo, F.; et al Diagnostic Criteria for Temporomandibular Disorders (DC/TMD) for Clinical and Research Applications: Recommendations of the International RDC/TMD Consortium Network* and Orofacial Pain Special Interest Groupdagger. J. Oral Facial Pain Headache 2014, 28, 6-27. [CrossRef] [PubMed]

32. Peck, C.C.; Goulet, J.P.; Lobbezoo, F.; Schiffman, E.L.; Alstergren, P.; Anderson, G.C.; de Leeuw, R.; Jensen, R.; Michelotti, A.; Ohrbach, R.; et al. Expanding the taxonomy of the diagnostic criteria for temporomandibular disorders. J. Oral Rehabil. 2014, 41, 2-23. [CrossRef] [PubMed]

33. Al-Saleh, M.A.; Alsufyani, N.A.; Saltaji, H.; Jaremko, J.L.; Major, P.W. MRI and CBCT image registration of temporomandibular joint: A systematic review. J. Otolaryngol. Head Neck Surg. 2016, 45, 30. [CrossRef]

34. Al-Saleh, M.A.; Jaremko, J.L.; Alsufyani, N.; Jibri, Z.; Lai, H.; Major, P.W. Assessing the reliability of MRI-CBCT image registration to visualize temporomandibular joints. Dentomaxillofac. Radiol. 2015, 44, 20140244. [CrossRef] [PubMed]

35. Ladeira, D.B.; da Cruz, A.D.; de Almeida, S.M. Digital panoramic radiography for diagnosis of the temporomandibular joint: CBCT as the gold standard. Braz. Oral Res. 2015, 29, S1806-83242015000100303. [CrossRef]

36. Larheim, T.A.; Abrahamsson, A.K.; Kristensen, M.; Arvidsson, L.Z. Temporomandibular joint diagnostics using CBCT. Dentomaxillofac. Radiol. 2015, 44, 20140235. [CrossRef]

37. Su, N.; van Wijk, A.J.; Visscher, C.M.; Lobbezoo, F.; van der Heijden, G. Diagnostic value of ultrasonography for the detection of disc displacements in the temporomandibular joint: A systematic review and meta-analysis. Clin. Oral Investig. 2018, 22, 2599-2614. [CrossRef]

38. Talmaceanu, D.; Lenghel, L.M.; Bolog, N.; Popa Stanila, R.; Buduru, S.; Leucuta, D.C.; Rotar, H.; Baciut, M.; Baciut, G. Highresolution ultrasonography in assessing temporomandibular joint disc position. Med. Ultrason. 2018, 1, 64-70. [CrossRef]

39. Choi, B.H.; Yoon, S.H.; Song, S.I.; Yoon, J.K.; Lee, S.J.; An, Y.S. Comparison of Diagnostic Performance Between Visual and Quantitative Assessment of Bone Scintigraphy Results in Patients With Painful Temporomandibular Disorder. Medicine 2016, 95, e2485. [CrossRef]

40. Epstein, J.B.; Rea, A.; Chahal, O. The use of bone scintigraphy in temporomandibular joint disorders. Oral Dis. 2002, 8, 47-53. [CrossRef] [PubMed]

41. Kang, J.H.; An, Y.S.; Park, S.H.; Song, S.I. Influences of age and sex on the validity of bone scintigraphy for the diagnosis of temporomandibular joint osteoarthritis. Int. J. Oral Maxillofac. Surg. 2018, 47, 1445-1452. [CrossRef] [PubMed]

42. Lee, Y.H.; Hong, I.K.; Chun, Y.H. Prediction of painful temporomandibular joint osteoarthritis in juvenile patients using bone scintigraphy. Clin. Exp. Dent. Res. 2019, 5, 225-235. [CrossRef] [PubMed]

43. Park, K.S.; Song, H.C.; Cho, S.G.; Kang, S.R.; Kim, J.; Jun, H.M.; Song, M.; Jeong, G.C.; Park, H.J.; Kwon, S.Y.; et al. Open-Mouth Bone Scintigraphy Is Better than Closed-Mouth Bone Scintigraphy in the Diagnosis of Temporomandibular Osteoarthritis. Nucl. Med. Mol. Imaging 2016, 50, 213-218. [CrossRef]

44. Chan, B.H.; Leung, Y.Y. SPECT bone scintigraphy for the assessment of condylar growth activity in mandibular asymmetry: Is it accurate? Int. J. Oral Maxillofac. Surg. 2018, 47, 470-479. [CrossRef] [PubMed]

45. Kumar, A.; Brennan, M.T. Differential diagnosis of orofacial pain and temporomandibular disorder. Dent. Clin. N. Am. 2013, 57, 419-428. [CrossRef]

46. Alpaslan, G.H.; Alpaslan, C. Efficacy of temporomandibular joint arthrocentesis with and without injection of sodium hyaluronate in treatment of internal derangements. J. Oral Maxillofac. Surg. 2001, 59, 613-618. [CrossRef]

47. Nitzan, D.W.; Dolwick, M.F.; Heft, M.W. Arthroscopic lavage and lysis of the temporomandibular joint: A change in perspective. J. Oral Maxillofac. Surg. 1990, 48, 798-801. [CrossRef]

48. Zhang, C.; Wu, J.Y.; Deng, D.L.; He, B.Y.; Tao, Y.; Niu, Y.M.; Deng, M.H. Efficacy of splint therapy for the management of temporomandibular disorders: A meta-analysis. Oncotarget 2016, 7, 84043-84053. [CrossRef] [PubMed] 
49. Riley, P.; Glenny, A.M.; Worthington, H.V.; Jacobsen, E.; Robertson, C.; Durham, J.; Davies, S.; Petersen, H.; Boyers, D. Oral splints for temporomandibular disorder or bruxism: A systematic review. Br. Dent. J. 2020, 228, 191-197. [CrossRef]

50. Al-Moraissi, E.A.; Farea, R.; Qasem, K.A.; Al-Wadeai, M.S.; Al-Sabahi, M.E.; Al-Iryani, G.M. Effectiveness of occlusal splint therapy in the management of temporomandibular disorders: Network meta-analysis of randomized controlled trials. Int. J. Oral Maxillofac. Surg. 2020, 49, 1042-1056. [CrossRef]

51. Alkhutari, A.S.; Alyahya, A.; Rodrigues Conti, P.C.; Christidis, N.; Al-Moraissi, E.A. Is the therapeutic effect of occlusal stabilization appliances more than just placebo effect in the management of painful temporomandibular disorders? A network meta-analysis of randomized clinical trials. J. Prosthet. Dent. 2020. [CrossRef] [PubMed]

52. Seifeldin, S.A.; Elhayes, K.A. Soft versus hard occlusal splint therapy in the management of temporomandibular disorders (TMDs). Saudi Dent. J. 2015, 27, 208-214. [CrossRef]

53. Incorvati, C.; Romeo, A.; Fabrizi, A.; Defila, L.; Vanti, C.; Gatto, M.R.A.; Marchetti, C.; Pillastrini, P. Effectiveness of physical therapy in addition to occlusal splint in myogenic temporomandibular disorders: Protocol of a randomised controlled trial. BMJ Open 2020, 10, e038438. [CrossRef]

54. van der Meer, H.A.; Calixtre, L.B.; Engelbert, R.H.H.; Visscher, C.M.; Nijhuis-van der Sanden, M.W.; Speksnijder, C.M. Effects of physical therapy for temporomandibular disorders on headache pain intensity: A systematic review. Musculoskelet. Sci. Pract. 2020, 50, 102277. [CrossRef] [PubMed]

55. Kutuk, S.G.; Ozkan, Y.; Kutuk, M.; Ozdas, T. Comparison of the Efficacies of Dry Needling and Botox Methods in the Treatment of Myofascial Pain Syndrome Affecting the Temporomandibular Joint. J. Craniofacial Surg. 2019, 30, 1556-1559. [CrossRef]

56. Connelly, S.T.; Myung, J.; Gupta, R.; Tartaglia, G.M.; Gizdulich, A.; Yang, J.; Silva, R. Clinical outcomes of Botox injections for chronic temporomandibular disorders: Do we understand how Botox works on muscle, pain, and the brain? Int. J. Oral Maxillofac. Surg. 2017, 46, 322-327. [CrossRef]

57. Kim, Y.H.; Bang, J.I.; Son, H.J.; Kim, Y.; Kim, J.H.; Bae, H.; Han, S.J.; Yoon, H.J.; Kim, B.S. Protective effects of extracorporeal shockwave on rat chondrocytes and temporomandibular joint osteoarthritis; preclinical evaluation with in vivo(99m)Tc-HDP SPECT and ex vivo micro-CT. Osteoarthr. Cartil. 2019, 27, 1692-1701. [CrossRef]

58. Schenk, I.; Vesper, M.; Nam, V.C. Initial results using extracorporeal low energy shockwave therapy ESWT in muscle reflexinduced lock jaw. Mund Kiefer Gesichtschir. 2002, 6, 351-355. [CrossRef] [PubMed]

59. Dworkin, S.F.; Turner, J.A.; Mancl, L.; Wilson, L.; Massoth, D.; Huggins, K.H.; LeResche, L.; Truelove, E. A randomized clinical trial of a tailored comprehensive care treatment program for temporomandibular disorders. J. Orofac. Pain 2002, 16, 259-276.

60. Türp, J.C.; Jokstad, A.; Motschall, E.; Schindler, H.J.; Windecker-Gétaz, I.; Ettlin, D.A. Is there a superiority of multimodal as opposed to simple therapy in patients with temporomandibular disorders? A qualitative systematic review of the literature. Clin. Oral Implant. Res. 2007, 18 (Suppl. 3), 138-150. [CrossRef]

61. Conti, P.C.; Correa, A.S.; Lauris, J.R.; Stuginski-Barbosa, J. Management of painful temporomandibular joint clicking with different intraoral devices and counseling: A controlled study. J. Appl. Oral Sci. 2015, 23, 529-535. [CrossRef]

62. de Resende, C.; de Oliveira Medeiros, F.G.L.; de Figueiredo Rego, C.R.; Bispo, A.S.L.; Barbosa, G.A.S.; de Almeida, E.O. Shortterm effectiveness of conservative therapies in pain, quality of life, and sleep in patients with temporomandibular disorders: A randomized clinical trial. Cranio 2019, 1-9. [CrossRef]

63. de Barros Pascoal, A.L.; de Freitas, R.; da Silva, L.F.G.; Oliveira, A.; Dos Santos Calderon, P. Effectiveness of Counseling on Chronic Pain Management in Patients with Temporomandibular Disorders. J. Oral Facial Pain Headache 2020, 34, 77-82. [CrossRef]

64. Delgado-Delgado, R.; Iriarte-Álvarez, N.; Valera-Calero, J.A.; Centenera-Centenera, M.B.; Garnacho-Garnacho, V.E.; GallegoSendarrubias, G.M. Association between temporomandibular disorders with clinical and sociodemographic features: An observational study. Int. J. Clin. Pract 2021, e13961. [CrossRef]

65. Al-Ani, Z. Occlusion and Temporomandibular Disorders: A Long-Standing Controversy in Dentistry. Prim. Dent. J. 2020, 9, 43-48. [CrossRef]

66. Manfredini, D.; Lombardo, L.; Siciliani, G. Temporomandibular disorders and dental occlusion. A systematic review of association studies: End of an era? J. Oral Rehabil. 2017, 44, 908-923. [CrossRef]

67. Kakudate, N.; Yokoyama, Y.; Sumida, F.; Matsumoto, Y.; Gordan, V.V.; Gilbert, G.H.; Velly, A.M.; Schiffman, E.L. Dentist Practice Patterns and Therapeutic Confidence in the Treatment of Pain Related to Temporomandibular Disorders in a Dental Practice-Based Research Network. J. Oral Facial Pain Headache 2017, 31, 152-158. [CrossRef] [PubMed]

68. Onishi, M. Arthroscopy of the temporomandibular joint (author's transl). Kokubyo Gakkai Zasshi 1975, 42, 207-213. [CrossRef] [PubMed]

69. Murakami, K.; Ono, T. Temporomandibular joint arthroscopy by inferolateral approach. Int. J. Oral Maxillofac. Surg. 1986, 15, 410-417. [CrossRef]

70. Sanders, B. Arthroscopic surgery of the temporomandibular joint: Treatment of internal derangement with persistent closed lock Oral Surg. Oral Med. Oral Pathol. 1986, 62, 361-372. [CrossRef]

71. Sanders, B.; Buoncristiani, R. Diagnostic and surgical arthroscopy of the temporomandibular joint: Clinical experience with 137 procedures over a 2-year period. J. Craniomandib. Disord.: Facial Oral Pain 1987, 1, 202-213.

72. McCain, J.P. Arthroscopy of the human temporomandibular joint. J. Oral Maxillofac. Surg. 1988, 46, 648-655. [CrossRef]

73. McCain, J.P.; Sanders, B.; Koslin, M.G.; Quinn, J.H.; Peters, P.B.; Indresano, A.T. Temporomandibular joint arthroscopy: A 6-year multicenter retrospective study of 4,831 joints. J. Oral Maxillofac. Surg. 1992, 50, 926-930. [CrossRef] 
74. Reston, J.T.; Turkelson, C.M. Meta-analysis of surgical treatments for temporomandibular articular disorders. J. Oral Maxillofac. Surg. 2003, 61, 3-10. [CrossRef]

75. Schiffman, E.L.; Velly, A.M.; Look, J.O.; Hodges, J.S.; Swift, J.Q.; Decker, K.L.; Anderson, Q.N.; Templeton, R.B.; Lenton, P.A.; Kang, W.; et al. Effects of four treatment strategies for temporomandibular joint closed lock. Int. J. Oral Maxillofac. Surg. 2014, 43, 217-226. [CrossRef]

76. Dimitroulis, G. Outcomes of temporomandibular joint arthroscopy in patients with painful but otherwise normal joints. $J$. Craniomaxillofac. Surg. 2015, 43, 940-943. [CrossRef]

77. McCain, J.P.; Hossameldin, R.H.; Srouji, S.; Maher, A. Arthroscopic discopexy is effective in managing temporomandibular joint internal derangement in patients with Wilkes stage II and III. J. Oral Maxillofac. Surg. 2015, 73, 391-401. [CrossRef]

78. Al-Moraissi, E.A. Arthroscopy versus arthrocentesis in the management of internal derangement of the temporomandibular joint: A systematic review and meta-analysis. Int. J. Oral Maxillofac. Surg. 2015, 44, 104-112. [CrossRef]

79. Liu, X.; Zheng, J.; Cai, X.; Abdelrehem, A.; Yang, C. Techniques of Yang's arthroscopic discopexy for temporomandibular joint rotational anterior disc displacement. Int. J. Oral Maxillofac. Surg. 2019, 48, 769-778. [CrossRef]

80. Machoň, V.; Levorová, J.; Hirjak, D.; Beňo, M.; Drahoš, M.; Foltán, R. Does arthroscopic lysis and lavage in subjects with Wilkes III internal derangement reduce pain? Oral Maxillofac. Surg. 2021. [CrossRef] [PubMed]

81. Nitzan, D.W.; Dolwick, M.F.; Martinez, G.A. Temporomandibular joint arthrocentesis: A simplified treatment for severe, limited mouth opening. J. Oral Maxillofac. Surg. 1991, 49, 1163-1167. [CrossRef]

82. Alpaslan, C.; Kahraman, S.; Guner, B.; Cula, S. Does the use of soft or hard splints affect the short-term outcome of temporomandibular joint arthrocentesis? Int J. Oral Maxillofac. Surg. 2008, 37, 424-427. [CrossRef] [PubMed]

83. Bayramoglu, Z; Tozoglu, S. Comparison of single- and double-puncture arthrocentesis for the treatment of temporomandibular joint disorders: A six-month, prospective study. Cranio 2019, 1-6. [CrossRef]

84. Carvajal, W.A.; Laskin, D.M. Long-term evaluation of arthrocentesis for the treatment of internal derangements of the temporomandibular joint. J. Oral Maxillofac. Surg. 2000, 58, 852-855. [CrossRef]

85. Diracoglu, D.; Saral, I.B.; Keklik, B.; Kurt, H.; Emekli, U.; Ozcakar, L.; Karan, A.; Aksoy, C. Arthrocentesis versus nonsurgical methods in the treatment of temporomandibular disc displacement without reduction. Oral Surg. Oral Med. Oral Pathol. Oral Radiol. Endod. 2009, 108, 3-8. [CrossRef] [PubMed]

86. Emshoff, R.; Rudisch, A. Determining predictor variables for treatment outcomes of arthrocentesis and hydraulic distention of the temporomandibular joint. J. Oral Maxillofac. Surg. 2004, 62, 816-823. [CrossRef]

87. Monje-Gil, F.; Nitzan, D.; Gonzalez-Garcia, R. Temporomandibular joint arthrocentesis. Review of the literature. Med. Oral Patol Oral Cir. Bucal 2012, 17, e575-e581. [CrossRef] [PubMed]

88. Neeli, A.S.; Umarani, M.; Kotrashetti, S.M.; Baliga, S. Arthrocentesis for the treatment of internal derangement of the temporomandibular joint. J. Maxillofac. Oral Surg. 2010, 9, 350-354. [CrossRef] [PubMed]

89. Nitzan, D.W.; Price, A. The use of arthrocentesis for the treatment of osteoarthritic temporomandibular joints. J. Oral Maxillofac. Surg. 2001, 59, 1154-1159. [CrossRef]

90. Nitzan, D.W.; Samson, B.; Better, H. Long-term outcome of arthrocentesis for sudden-onset, persistent, severe closed lock of the temporomandibular joint. J. Oral Maxillofac. Surg. 1997, 55, 151-157. [CrossRef]

91. Nitzan, D.W.; Svidovsky, J.; Zini, A.; Zadik, Y. Effect of Arthrocentesis on Symptomatic Osteoarthritis of the Temporomandibular Joint and Analysis of the Effect of Preoperative Clinical and Radiologic Features. J. Oral Maxillofac. Surg. 2017, 75, 260-267. [CrossRef]

92. Polat, M.E.; Yanik, S. Efficiency of arthrocentesis treatment for different temporomandibular joint disorders. Int. J. Oral Maxillofac. Surg. 2020, 49, 621-627. [CrossRef]

93. Toameh, M.H.; Alkhouri, I.; Karman, M.A. Management of patients with disk displacement without reduction of the temporomandibular joint by arthrocentesis alone, plus hyaluronic acid or plus platelet-rich plasma. Dent. Med. Probl. 2019, 56, 265-272. [CrossRef]

94. Yilmaz, O.; Korkmaz, Y.T.; Tuzuner, T. Comparison of treatment efficacy between hyaluronic acid and arthrocentesis plus hyaluronic acid in internal derangements of temporomandibular joint. J. Craniomaxillofac. Surg. 2019, 47, 1720-1727. [CrossRef]

95. Vos, L.M.; Huddleston Slater, J.J.; Stegenga, B. Arthrocentesis as initial treatment for temporomandibular joint arthropathy: A randomized controlled trial. J. Craniomaxillofac. Surg. 2014, 42, e134-e139. [CrossRef] [PubMed]

96. Al-Moraissi, E.A.; Wolford, L.M.; Ellis, E., 3rd; Neff, A. The hierarchy of different treatments for arthrogenous temporomandibular disorders: A network meta-analysis of randomized clinical trials. J. Craniomaxillofac. Surg. 2020, 48, 9-23. [CrossRef] [PubMed]

97. Li, D.T.S.; Wong, N.S.M.; Li, S.K.Y.; McGrath, C.P.; Leung, Y.Y. Timing of Arthrocentesis in the Management of Temporomandibular Disorders: An Integrative Review and Meta-analysis. Int. J. Oral Maxillofac. Surg. 2021. [CrossRef]

98. Hobeich, J.B.; Salameh, Z.A.; Ismail, E.; Sadig, W.M.; Hokayem, N.E.; Almas, K. Arthroscopy versus arthrocentesis. A retrospective study of disc displacement management without reduction. Saudi Med. J. 2007, 28, 1541-1544. [PubMed]

99. Laskin, D.M. Arthroscopy Versus Arthrocentesis for Treating Internal Derangements of the Temporomandibular Joint. Oral Maxillofac. Surg. Clin. N. Am. 2018, 30, 325-328. [CrossRef]

100. Monteiro, J.; de Arruda, J.A.A.; Silva, E.; Vasconcelos, B. Is Single-Puncture TMJ Arthrocentesis Superior to the Double-Puncture Technique for the Improvement of Outcomes in Patients With TMDs? J. Oral Maxillofac. Surg. 2020, 78, 1319.e1311-1319.e1315. [CrossRef] [PubMed] 
101. Nagori, S.A.; Roy Chowdhury, S.K.; Thukral, H.; Jose, A.; Roychoudhury, A. Single puncture versus standard double needle arthrocentesis for the management of temporomandibular joint disorders: A systematic review. J. Oral Rehabil. 2018, 45, 810-818. [CrossRef]

102. Folle, F.S.; Poluha, R.L.; Setogutti, E.T.; Grossmann, E. Double puncture versus single puncture arthrocentesis for the management of unilateral temporomandibular joint disc displacement without reduction: A randomized controlled trial. J. Craniomaxillofac. Surg. 2018, 46, 2003-2007. [CrossRef] [PubMed]

103. Bhargava, D.; Thomas, S.; Pawar, P.; Jain, M.; Pathak, P. Ultrasound-guided arthrocentesis using single-puncture, double-lumen, single-barrel needle for patients with temporomandibular joint acute closed lock internal derangement. Oral Maxillofac. Surg. 2019, 23, 159-165. [CrossRef]

104. Antony, P.G.; Sebastian, A.; Annapoorani, D.; Varghese, K.G.; Mohan, S.; Jayakumar, N.; Dominic, S.; John, B. Comparison of clinical outcomes of treatment of dysfunction of the temporomandibular joint between conventional and ultrasound-guided arthrocentesis. Br. J. Oral Maxillofac. Surg. 2019, 57, 62-66. [CrossRef]

105. Bilgir, E.; Yildirim, D.; Senturk, M.F.; Orhan, H. Clinical and ultrasonographic evaluation of ultrasound-guided single puncture temporomandibular joint arthrocentesis. Cranio 2020, 1-10. [CrossRef]

106. Hu, Y.; Zhang, X.; Liu, S.; Xu, F. Ultrasound-guided vs conventional arthrocentesis for management of temporomandibular joint disorders: A systematic review and meta-analysis. Cranio 2020. [CrossRef]

107. Leung, Y.Y.; Wu, F.H.W.; Chan, H.H. Ultrasonography-guided arthrocentesis versus conventional arthrocentesis in treating internal derangement of temporomandibular joint: A systematic review. Clin. Oral Investig. 2020, 24, 3771-3780. [CrossRef]

108. Haigler, M.C.; Abdulrehman, E.; Siddappa, S.; Kishore, R.; Padilla, M.; Enciso, R. Use of platelet-rich plasma, platelet-rich growth factor with arthrocentesis or arthroscopy to treat temporomandibular joint osteoarthritis: Systematic review with meta-analyses. J. Am. Dent. Assoc. 2018, 149, 940-952.e942. [CrossRef]

109. Liu, Y.; Wu, J.S.; Tang, Y.L.; Tang, Y.J.; Fei, W.; Liang, X.H. Multiple Treatment Meta-Analysis of Intra-Articular Injection for Temporomandibular Osteoarthritis. J. Oral Maxillofac. Surg. 2020, 78, 373.e371-373.e318. [CrossRef]

110. Chowdhury, S.K.R.; Saxena, V.; Rajkumar, K.; Shadamarshan, R.A. Evaluation of Total Alloplastic Temporomandibular Joint Replacement in TMJ Ankylosis. J. Maxillofac. Oral Surg. 2019, 18, 293-298. [CrossRef]

111. Bhargava, D.; Neelakandan, R.S.; Dalsingh, V.; Sharma, Y.; Pandey, A.; Pandey, A.; Beena, S.; Koneru, G. A three dimensional (3D) musculoskeletal finite element analysis of DARSN temporomandibular joint (TMJ) prosthesis for total unilateral alloplastic joint replacement. J. Stomatol. Oral Maxillofac. Surg. 2019, 120, 517-522. [CrossRef] [PubMed]

112. Mercuri, L.G. Costochondral Graft Versus Total Alloplastic Joint for Temporomandibular Joint Reconstruction. Oral Maxillofac. Surg. Clin. N. Am. 2018, 30, 335-342. [CrossRef]

113. Lotesto, A.; Miloro, M.; Mercuri, L.G.; Sukotjo, C. Status of alloplastic total temporomandibular joint replacement procedures performed by members of the American Society of Temporomandibular Joint Surgeons. Int. J. Oral Maxillofac. Surg. 2017, 46, 93-96. [CrossRef] [PubMed]

114. Ramos, A.; Mesnard, M. Christensen vs Biomet Microfixation alloplastic TMJ implant: Are there improvements? A numerical study. J. Craniomaxillofac. Surg. 2015, 43, 1398-1403. [CrossRef]

115. Neelakandan, R.S.; Raja, A.V.; Krishnan, A.M. Total Alloplastic Temporomandibular Joint Reconstruction for Management of TMJ Ankylosis. J. Maxillofac. Oral Surg. 2014, 13, 575-582. [CrossRef]

116. Burgess, M.; Bowler, M.; Jones, R.; Hase, M.; Murdoch, B. Improved outcomes after alloplastic TMJ replacement: Analysis of a multicenter study from Australia and New Zealand. J. Oral Maxillofac. Surg. 2014, 72, 1251-1257. [CrossRef] [PubMed] 